\title{
High-Risk Coronary Revascularization in a Patient with Acute Myocardial Infarction - Culprit Lesion in Last Remaining Vessel - Case Report
}

\section{Juliana Senftinger ${ }^{1}$ | Peter Clemmensen ${ }^{1,2,3}$ | Stefan Blankenberg ${ }^{1,2}$ | Christina Magnussen ${ }^{1,2 *}$}

\section{*Correspondence: Christina Magnussen}

Address: ${ }^{1}$ Department of Cardiology, University Heart and Vascular Center Hamburg, Hamburg, Germany; ${ }^{2}$ German Center for Cardiovascular Research (DZHK), partner site Hamburg/Kiel/Luebeck, Germany; ${ }^{3}$ Faculty of Health Sciences, Department of Regional Health Research, University of Southern Denmark, Odense and Nykoebing F Hospital, Denmark

e-mail $\bowtie$ : c.magnussen@uke.de

Received: 20 January 2021; Accepted: 01 February 2021

Copyright: (C) 2021 Senftinger J. This is an open-access article distributed under the terms of the Creative Commons Attribution License, which permits unrestricted use, distribution, and reproduction in any medium, provided that the original work is properly cited.

\section{ABSTRACT}

There is still conflicting evidence concerning the optimal therapeutic approach during cardiogenic shock in patients with acute myocardial infarction.

We present a case of non-ST-segment elevation myocardial infarction with the RCA deemed culprit lesion due to absence of collaterals to the chronically occluded LAD and CFX. The 71-year-old patient presented to chest-pain-unit with angina pectoris Canadian Cardiovascular Society (CCS) grading III. Severe 2-vessel coronary artery disease was already diagnosed in 2014 with recommendation for coronary artery bypass grafting (CABG). However, the patient refused CABG at the time because of freedom from symptoms. Despite full revascularization by percutaneous coronary angioplasty (PCI) and mechanical circulatory support with Impella and extracorporeal membrane oxygenation, the patient died a few days later because of progressive hemodynamic decline and severe vascular complications.

While using mechanical circulatory support during cardiogenic shock, several complications especially vascular complications are to be expected. Therefore, we should aim to remove the Impella as soon as possible or if further needed consider switching it to central Impella. Furthermore, it remains questionable to what extent recanalization of chronic total occlusions (CTO) in cardiogenic shock impact patient outcomes.

Keywords: Acute Coronary Syndrome, Chronic Total Occlusion, Cardiogenic Shock, Mechanical Circulatory Support, Case Report

\section{Introduction}

Cardiogenic shock (CS) following myocardial infarction (MI) is a life-threatening complication with a mortality up to about 40-50\% (Ouweneel et al., 2017). In patients with multivessel coronary artery disease (CAD) recent investigations show that after intervention of the culprit lesion, revascularization of the remaining stenosis should be achieved in a two-staged procedure (Thiele $e t$ al., 2017). 
Nevertheless, pex`rcutaneous mechanical circulatory support (MCS) is often required but frequently limited by severe complications. We report on a patient with acute MI due to severe 3-vessel CAD and progressive hemodynamic decline despite MCS and full coronary and peripheral revascularization.

\section{Case Presentation}

A 71-year-old man presented at the chest pain unit with angina pectoris CCS III and known 3vessel CAD.

On examination, the patient was hemodynamically stable with a heart rate of 69 beats $/ \mathrm{min}$ and a blood pressure of 161/87 mmHg. An electrocardiogram was recorded showing sinus rhythm and Tinversions in I, aVL, V4-6 (Fig. 1).

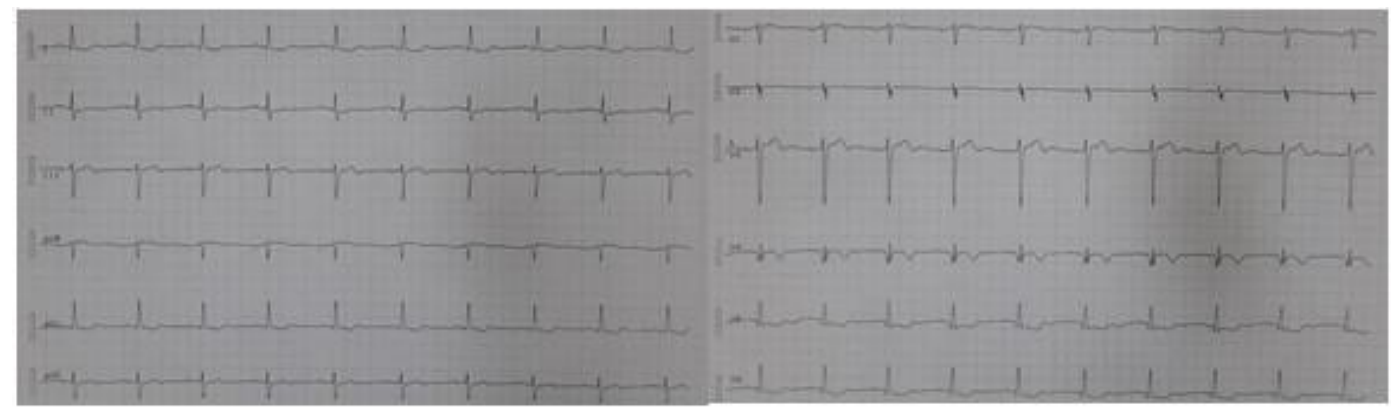

Figure 1: 12-lead electrocardiogram on presentation with T-inversions in I, aVL, V4-6

The blood work revealed elevated cardiac ischemic markers with a significant increase in troponin from 294 to $790 \mathrm{pg} / \mathrm{ml}$ and creatine kinase from 141 to $383 \mathrm{U} / \mathrm{l}$ within 3 hours. Compared to May 2018, the echocardiography at presentation showed a deterioration of the left ventricular function (EF 35\%) with still preserved right ventricular function, but novel apical and septal wall movement disorders.

Two-vessel CAD was known since 1999. A cardiac checkup in 2014 revealed a pathological ergometry with ST-segment-depression in II, aVF, V4-5. The consecutive angiography showed new $90 \%$ concentric stenosis of LAD and functional occlusion of CFX with an indication for coronary artery bypass grafting (CABG). In May 2018, an inguinal hernia was diagnosed with the recommendation for surgery. For preoperative risk stratification, the patient was referred to our cardiology outpatient clinic; because of stable angina pectoris CCS II and known untreated 2-vessel CAD, coronary angiography was performed. A further progression was demonstrated now with new chronic total occlusion (CTO) of the mid-LAD and RPLD and new high-degree stenoses of RCA. Both times, the patient refused the proposed CABG. He was discharged with aspirin, statin, and angiotensin-receptor-blocker due to hypertension. 
Due to non-ST-segment elevation myocardial infarction (NSTEMI) a coronary angiogram was performed on 14/11/2018 and showed the RCA as culprit-lesion with failing of collateralization to LCA (Fig. 2). After an interdisciplinary discussion with our cardiac surgeons, again CABG was recommended and this time the patient agreed. The patient was hemodynamically stable and asymptomatic so that surgery was planned for the next day.

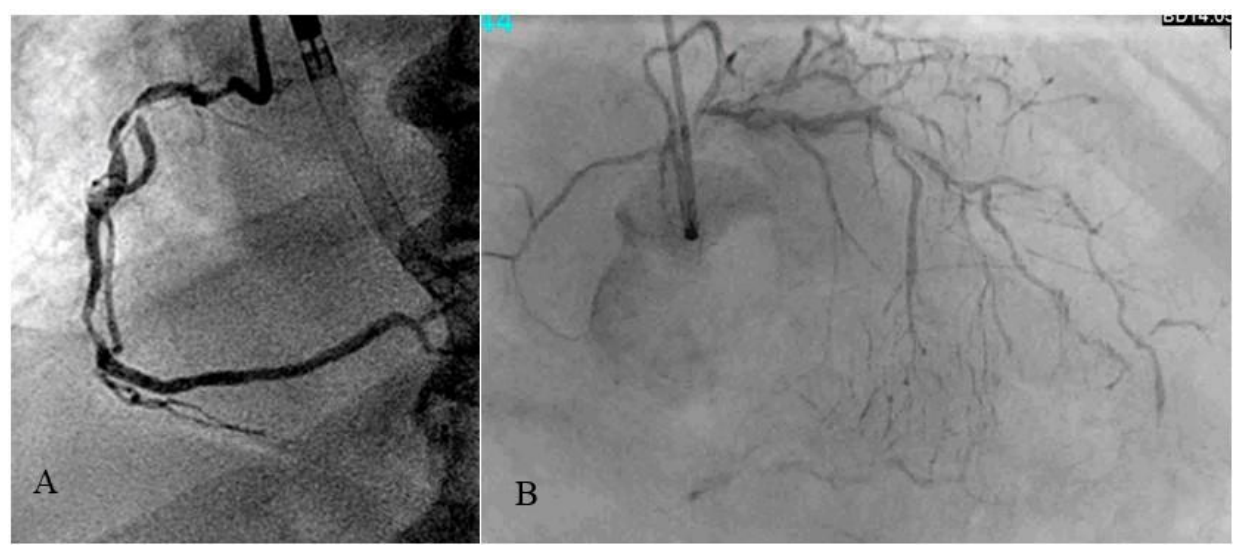

Figure 2: (A) Long segment stenosis of the RCA; (B) CTO of LAD and CFX collateralized by RCA

The following morning, the patient showed an exponential increase of the cardiac markers with a troponin value of $9189 \mathrm{pg} / \mathrm{ml}$ and creatine kinase of $1762 \mathrm{U} / \mathrm{l}$. Furthermore, he developed ST-segmentelevation in II, III, aVF with beginning CS so that CABG was turned down. Angiography of the femoral artery proved adequate perfusion and sufficient lumen diameter and helped to precisely assess the best position for Impella insertion. An Impella CP was then inserted through the right femoral artery and a long-segment percutaneous coronary intervention (PCI) of the RCA was performed. After balloondilatation, the vessel showed no-reflow despite the administration of high-doses of nitroglycerin and adenosine (Fig. 3). After the procedure, the patient could be transferred hemodynamically stable to our intensive care unit, albeit with Impella and positive inotropic therapy support with dobutamine.
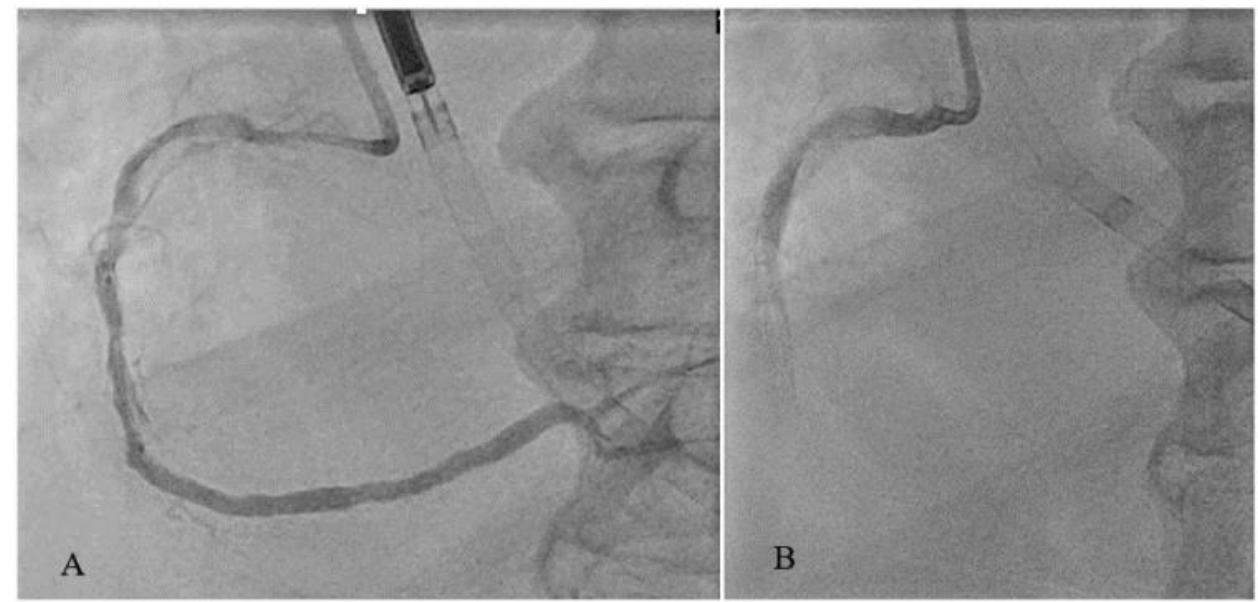

Figure 3: Coronary angiography 15/11/2018 - (A) PCI of RCA, (B) RCA with no-reflow after intervention 
The second-look coronary angiography five days later showed reperfusion of the RCA. Furthermore, an antegrade recanalization of LAD with PCI of the left main and LAD was accomplished (Fig. 4).

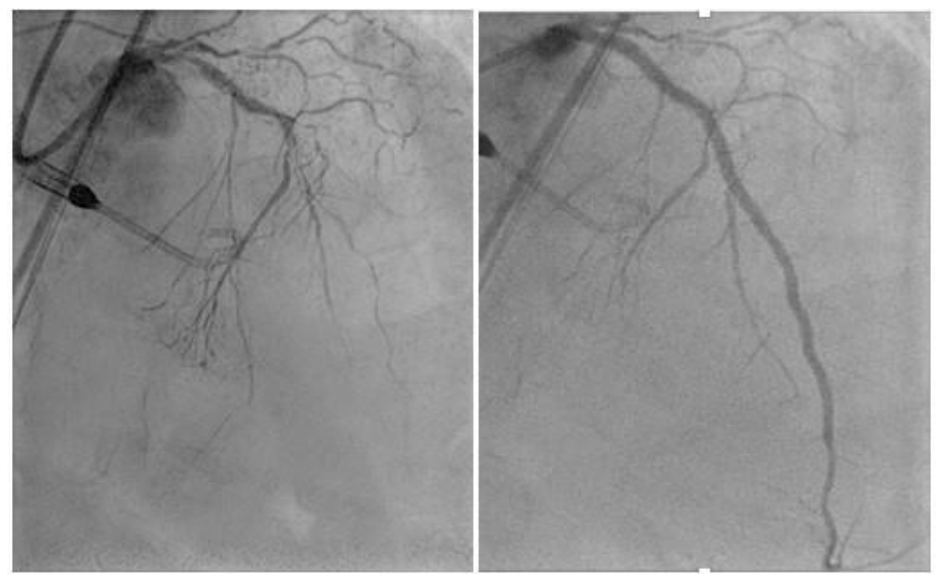

Figure 4: Coronary angiography 20/11/2018 - Antegrade recanalization of LAD

The following day, the Impella CP was removed due to hemodynamic stabilization. A few hours later, the patient presented critical ischemia of the right leg. The computed tomography angiography proved a thromboembolic occlusion of the right common iliac artery and a local dissection of the proximal left common iliac artery. An embolectomy was planned. During anesthesia introduction, the patient got hemodynamically compromised with a need for cardiopulmonary resuscitation. After return of spontaneous circulation, an orientational echocardiography showed a severely depressed left and right ventricular function. An extracorporeal membrane oxygenation (ECMO) was implanted through the left common femoral artery and right femoral vein with bilateral antegrade leg perfusion.

The echocardiographic follow-up showed a progressive dilatation of the left ventricle, as well as deterioration of the right ventricular function. Additionally, compartment syndrome of the right leg became obvious due to venous congestion. An Impella 5.0 was now introduced through the right subclavian artery and a fasciotomy of the right leg was performed. The next day, the ECMO had to be removed due to the compartment syndrome. Because of vascular complications of both iliac arteries, an axillo-bifemoral-bypass was established. However, the patient suffered from progressive CS. After full coronary and peripheral revascularization and because of a lack of further therapeutic options, the patient died three days later.

\section{Discussion}

The optimal therapeutic approach during CS following MI still needs further investigation regarding strategies of revascularization and MCS. In the presented case even complete 
revascularization and simultaneous usage of ECMO and Impella couldn't prevent the fatal outcome of the patient.

Long-lasting experience exists with ECMO without equal alternatives yet as it is the fastest method to stabilize a patient in a shock situation. However, ECMO causes elevated afterload which leads to a dilatation of the left ventricle. In contrast, the Impella is a very effective device to unload the left ventricle (Schrage and Westermann, 2019). In a retrospective analysis, the addition of Impella to ECMO seems to improve survival by reducing afterload and increasing net forward flow (Pappalardo et al., 2017). However, there is still conflicting evidence regarding the mortality benefit of the simultaneous use of Impella and ECMO (Schrage and Westermann, 2019).

The incidence of vascular complications caused by Impella is described in 4-17\%, amongst others bleeding, pseudoaneurysm and acute limb ischemia which contributed in our case to the fatal outcome (Abaunza et al., 2015). There are several reasons in our case for increased risk for limb ischemia. First, hypoperfusion during CS which enhances stasis of the blood flow. Together with alternation of blood clotting during systemic inflammatory response syndrome in this shock situation as well as exposure to a foreign body in the vessel enhance the risk for thromboembolism. To reduce the risk of complications, the manufacturer recommends to remove the Impella 2.5 and CP after 4 days and Impella 5.0 after 6 days (ABIOMED | Impella $\left.{ }^{\circledR}\right)$. The longer the Impella stays in situ the higher the risk for complications (Abaunza et al., 2015). In our case, we had to leave it for a total of 6 days because of prolonged hemodynamic instability. So that it might have been an option to early and electively switch the Impella $\mathrm{CP}$ to a central device. One possibility is a transaxillary approach which seems to be a feasible and safe alternative: no vascular complications were described in the analyzed cases (Boll et al., 2019). In the beginning, only operative implantation of the Impella in a transaxillary position was described. But recently also a percutaneous transaxillary approach was successfully achieved. Those Impellas stayed also for a longer time up to 22 days. This approach has only been described in a few cases and it is technically challenging (Mathur et al., 2016).

After PCI of the RCA, cardiac tissue failed to perfuse normally. It is known that no-reflow is associated with a higher risk for left ventricular dysfunction, congestive heart failure, and death (Ito et al., 1992). The underlying mechanism is assumed to be endothelial dysfunction with tissue edema, releasing of vasoconstrictors by damaged cells, and microemboli of atherosclerotic debris (Niccoli et al., 2009). A beneficial role to treat no-reflow has been demonstrated for the intracoronary application of calcium channel blockers, adenosine and nitroprusside, as well as for Glycoprotein IIb/IIIa inhibitors and nitroglycerine (Scarpone et al., 2018). Here we administrated high dose adenosine and nitroglycerin which had no acute effect in our case. Furthermore, in our case repeated pre-dilatation 
possibly caused dissection or higher-degree endothelial damage followed by no-reflow which just couldn't be proved in the performed intravascular ultrasound.

After PCI of the culprit-lesion, we chose to recanalize the LAD in a two-staged approach. As the CULPRIT-SHOCK trial demonstrated, PCI of the culprit-lesion only in the initial intervention led to less renal replacement therapy as well as less composite death in a timeframe of 30 days compared to immediate multivessel PCI in patients with CS following MI (Thiele et al., 2017). However, long-term follow-up seems to show no significant difference concerning mortality but more rehospitalizations due to heart failure and more revascularizations had to be performed in the culprit lesion only group (Thiele et al., 2018). Concerning CTOs, there is still conflicting evidence regarding the optimal therapeutic approach during CS. In an elective setting recanalization of CTOs improves survival through better preserved left ventricular ejection fraction (Hoebers et al., 2015). Subgroup analyses of the CULPRITSHOCK trial though suggest no benefit of an early revascularization of CTOs in a shock situation (Thiele et al., 2017). In our case, the recanalization of the CTO was successful but couldn't prevent progressive hemodynamic decline. Even if PCI of the CTO might improve functionality possibly through better perfusion, the benefit of recanalization in the setting of CS might be overestimated. However, this needs further investigation.

The patient presented several risk factors for increased mortality. First of all, the advanced age of 71 years even if he led an active lifestyle. Furthermore, the exponential increase of the cardiac markers with a troponin value of $9189 \mathrm{pg} / \mathrm{ml}$ and creatine kinase of $1762 \mathrm{U} / \mathrm{l}$, as well as beginning CS (Fox et al., 2006). Another risk factor for the poor prognostic outcome is the impaired left ventricular function at presentation and the no-reflow phenomenon after PCI of the RCA (Ito et al., 1992; Ibanez et al., 2018).

Ultimately, we have to consider to what extent we need to urge a patient to undergo a guidelinebased and necessarily indicated therapy in an elective setting. CABG was offered him twice before and rejected because of freedom of symptoms. In this case, the patient wasn't aware of the seriousness of his disease. Maybe further information and education concerning the disease at an earlier stage would have been necessary to prevent the fatal course.

In conclusion, we should aim to remove Impella $\mathrm{CP}$ as soon as possible to prevent thromboembolic complications. If Impella support is further needed, a switch to a central Impella should be considered as it seems to be a safe strategy. Moreover, it is questionable to what extent a recanalization of CTOs in CS is beneficial. Maybe it's only coronary "cosmetics"; nevertheless, patients who undergo such a procedure have to be well selected. 


\section{Learning Objectives}

- $\quad$ Optimal therapeutic approach during cardiogenic shock is still challenging.

- Removal of the Impella CP as soon as possible or switch to a central Impella to prevent thromboembolic complications.

- Further evidence is needed to evaluate the benefit of recanalization of CTOs during cardiogenic shock.

\section{Abbreviations and Acronyms}

$\mathrm{CABG}=$ Coronary artery bypass grafting

$\mathrm{CAD}=$ Coronary artery disease

CCS $=$ Canadian Cardiovascular Society

$\mathrm{CS}=$ Cardiogenic shock

$\mathrm{CTO}=$ Chronic total occlusion

ECMO = Extracorporeal membrane oxygenation

MCS = Mechanical circulatory support

$\mathrm{MI}=$ Myocardial infarction

NSTEMI = Non-ST-segment elevation myocardial infarction

$\mathrm{PCI}=$ Percutaneous coronary intervention

\section{Timeline}

\begin{tabular}{|c|c|}
\hline 2014 & $\begin{array}{l}\text { 3-vessel CAD with recommendation for Coronary Artery Bypass Grafting (CABG); Patient's refusal } \\
\text { because of freedom from symptoms }\end{array}$ \\
\hline $14 / 05 / 2018$ & Progress of CAD; Again, refusal of CABG \\
\hline $14 / 11 / 2018$ & $\begin{array}{l}\text { The patient presented with angina pectoris CCS III. Non-ST-Segment elevation myocardial infarction } \\
\text { (NSTEMI) was diagnosed with RCA as culprit lesion; CABG planned for the following morning }\end{array}$ \\
\hline $15 / 11 / 2018$ & $\begin{array}{l}\text { Exponential increase of cardiac markers with ST-segment elevation, CABG turned down by cardiac } \\
\text { surgeons; Emergency setting with implantation of Impella CP via the right femoral artery and } \\
\text { percutaneous coronary intervention (PCI) of RCA with no-reflow }\end{array}$ \\
\hline $20 / 11 / 2018$ & $\begin{array}{l}\text { Second-look coronary angiography with reperfusion of RCA; Recanalization of Chronic Total Occlusion } \\
\text { (CTO) of LAD }\end{array}$ \\
\hline $21 / 11 / 2018$ & $\begin{array}{l}\text { Removal of Impella CP due to hemodynamic stabilization; subsequent critical ischemia of the right leg } \\
\text { due to thromboembolic occlusion of the right common iliac artery; Cardiopulmonary resuscitation } \\
\text { (CPR) during anesthesia introduction for thrombectomy with following ECMO implantation via the left } \\
\text { common femoral artery and right femoral vein }\end{array}$ \\
\hline $24 / 11 / 2018$ & $\begin{array}{l}\text { Venous congestion of the right leg due to venous ECMO cannula; Compartment syndrome and } \\
\text { fasciotomy right leg and Implantation of Impella } 5.0 \text { through the right subclavian artery }\end{array}$ \\
\hline $25 / 11 / 2018$ & ECMO explantation due to compartment syndrome; Axillo-bifemoral bypass \\
\hline $28 / 11 / 2018$ & Progressive cardiogenic shock with no further escalation strategy; death of patient \\
\hline
\end{tabular}




\section{References}

Abaunza M, Kabbani LS, Nypaver T, Greenbaum A, Balraj P, Qureshi S, Alqarqaz MA, Shepard AD. Incidence and prognosis of vascular complications after percutaneous placement of left ventricular assist device. J Vasc Surg 2015; 62: 417423.

ABIOMED | Impella® Available at: http://www.abiomed.com/impella [Accessed October 18, 2019].

Boll G, Fischer A, Kapur NK, Salehi P. Right Axillary Artery Conduit Is a Safe and Reliable Access for Implantation of Impella 5.0 Microaxial Pump. Ann Vasc Surg 2019; 54: 54-59.

Fox KA, Dabbous OH, Goldberg RJ, Pieper KS, Eagle KA, Van de Werf F, Avezum Á, Goodman SG, Flather MD, Anderson FA, Granger CB. Prediction of risk of death and myocardial infarction in the six months after presentation with acute coronary syndrome: prospective multinational observational study (GRACE). BMJ 2006; 333: 1091.

Hoebers LP, Claessen BE, Elias J, Dangas GD, Mehran R, Henriques JP. Meta-analysis on the impact of percutaneous coronary intervention of chronic total occlusions on left ventricular function and clinical outcome. Int J Cardiol 2015; 187: 9096.

Ibanez B, James S, Agewall S, Antunes MJ, Bucciarelli-Ducci C, Bueno H, Caforio AL, Crea F, Goudevenos JA, Halvorsen S, Hindricks G. 2017 ESC Guidelines for the management of acute myocardial infarction in patients presenting with ST-segment elevation. Eur Heart J 2018; 39: 119-177.

Ito H, Tomooka T, Sakai N, Yu H, Higashino Y, Fujii K, Masuyama T, Kitabatake A, Minamino T. Lack of myocardial perfusion immediately after successful thrombolysis: A predictor of poor recovery of left ventricular function in anterior myocardial infarction. Circulation 1992; 85: 1699-1705.

Mathur M, Hira RS, Smith BM, Lombardi WL, McCabe JM. Fully Percutaneous Technique for Transaxillary Implantation of the Impella CP. JACC Cardiovasc Interv 2016; 9: 1196-1198.

Niccoli G, Burzotta F, Galiuto L, Crea F. Myocardial No-Reflow in Humans. J Am Coll Cardiol 2009; 54: 281-292.

Ouweneel DM, Eriksen E, Sjauw KD, van Dongen IM, Hirsch A, Packer EJ, Vis MM, Wykrzykowska JJ, Koch KT, Baan J, de Winter RJ. Percutaneous Mechanical Circulatory Support Versus Intra-Aortic Balloon Pump in Cardiogenic Shock After Acute Myocardial Infarction. J Am Coll Cardiol 2017; 69: 278-287.

Pappalardo F, Schulte C, Pieri M, Schrage B, Contri R, Soeffker G, Greco T, Lembo R, Müllerleile K, Colombo A, Sydow K. Concomitant implantation of Impella $®$ on top of veno-arterial extracorporeal membrane oxygenation may improve survival of patients with cardiogenic shock. Eur J Heart Fail 2017; 19: 404-412.

Scarpone M, Cenko E, Manfrini O. Coronary No-Reflow Phenomenon in Clinical Practice. Curr Pharm Des 2018; 24: 29272933.

Schrage B and Westermann D. Mechanical circulatory support devices in cardiogenic shock and acute heart failure. Curr Opin Crit Care 2019; 25, 391-396.

Thiele H, Akin I, Sandri M, de Waha-Thiele S, Meyer-Saraei R, Fuernau G, Eitel I, Nordbeck P, Geisler T, Landmesser U, Skurk C (2018). One-year outcomes after PCI strategies in cardiogenic shock. N Engl J Med 379: 1699-1710.

Thiele H, Akin I, Sandri M, Fuernau G, de Waha S, Meyer-Saraei R, Nordbeck P, Geisler T, Landmesser U, Skurk C, Fach A. PCI strategies in patients with acute myocardial infarction and cardiogenic shock. N Engl J Med 2017; 377: 419-2432. 